\title{
EL PLACER EN LA INVESTIGACIÓN EN EDUCACIÓN: TRÁNSITOS AFECTIVOS Y AFECTANTES COMO ERÓTICAS DEL RIGOR
}

\author{
Francisco Ramallo ${ }^{\mathrm{i}}$ \\ Luciana Berengeno ${ }^{\text {ii }}$ \\ María Marta Yedaide ${ }^{\mathrm{iii}}$
}

\begin{abstract}
Resumen: En la interrogación sobre las maneras de narrar la docencia universitaria, los tránsitos afectivos y afectantes que fluyen entre disciplinas y lenguajes en el Grupo de Investigaciones en Cultura, Educación Superior y Disciplinas Proyectuales del que formamos parte en la Facultad de Arquitectura, Urbanismo y Diseño de la Universidad Nacional de Mar del Plata, suscitan promiscuidades a contrapelo del rigor clásico de la investigación. La erotización del conocimiento deviene de componer una agenda sobre el placer en la docencia universitaria, que avivamos en este artículo desde una reflexión a propósito de relatos cruzados de dispositivos específicos: diarios etnográficos de observación de clases de pares. En este texto aludimos a la erótica para abrazar una práctica de investigación creativa, sensible a la inmediatez de los vínculos afectivos en los que se goza la enseñanza universitaria y su poética de saberes.
\end{abstract}

Palabras clave: Educación; Enseñanza universitaria; Erótica, Investigación narrativa.

\section{PLEASURE IN EDUCATION RESEARCH: AFFECTIVE AND AFFECTING TRANSITS AS EROTIC OF RIGOR}

\begin{abstract}
In the process of questioning the alternatives to narrating university teaching, it has become possible to observe certain affecting and affected itineraries in- between disciplines and languages in the Research Group on Culture, Higher Education and Project-Design Disciplines to which we belong and which is set at the School of Architecture, Urbanism and Design, Mar del Plata State University. In such context, promiscuity of knowledges and academic interchanges has defied classical research rigor, as we have composed an agenda that comprises pleasure as a phenomenon to track down and approach. Eroticized knowledge is presented here through the stories written about some participant observation registers in a variety of educational settings within the University. The experience we hereby address paves the way for an erotic understanding of research, which includes creative practices that are sensitive to the affective relationships embedded in the immediate contexts.
\end{abstract}

Keywords: Education; University Teaching; Erotic; Narrative Research.

\section{Introducción: girando hacia la erótica en la educación universitaria}

El texto que usted escribe debe probarme que me desea. Esa prueba existe: es la escritura. La escritura es esto: la ciencia de los goces del lenguaje, su kamasutra -de esta ciencia no hay más que un tratado: la escritura misma. (BARTHES, 2008; p. 14) 
Esta cita propone un destello de "justicia erótica" (RUBIN, 2018; FLORES, 2018), elaborada en el texto que comienza en y para el estudio de la enseñanza universitaria; así, nos anima a reconocernos como educadorxs preocupados por interrumpir los impolutos, desexualizados e incontaminados placeres de la carne en el trabajo académico. Con este gesto erótico habitamos a la investigación, especialmente la investigación narrativa, en la Facultad de Arquitectura, Urbanismo y Diseño de la Universidad Nacional de Mar del Plata como un modo (otro) de conocer, ser y saber que canaliza la expresión subjetiva de nuestros cuerpos, deseos y placeres. A la manera de una reparación de la desafectivización promovida en la investigación clásica, nuestro trabajo en este enclave territorial propicia que los pliegues de la narrativa flexibilicen la rigidez académico-científica y la "justica erótica" descomponga la representación de la realidad. Estas otras formas de comprender lo real -más bien las realidades- develan abordajes atentos para el análisis de las (auto)interpretaciones y comprensiones sociales de nosotros mismos como sujetxs materiales y ficcionales.

La primera persona erótica entrama las dimensiones sexual, afectiva, corporal, contextual, temporal y biográfica para reparar sensaciones y percepciones, a través de los sentidos que promueven la autopercepción del cuerpo en los procesos investigativos/creativos. Con un creciente interés por registrar nuestras relaciones eróticas y erotizantes en la investigación -tanto sobre la educación formal e informal, como así también por el interés en capturar (otras) prácticas y discursos que emergen a partir de las formas de educar no institucionalizadas- en el Grupo de Investigaciones en Cultura, Educación Superior y Disciplinas Proyectuales (en adelante CESDIP) promovemos el tránsito hacia formas de conocer(se), de pensar(se) y de sentir(se), con unx mismx y con lxs otrxs, que posibilitan descomponer los caminos más rígidos y más frecuentemente recorridos en la investigación contemporánea.

Todo ello abreva de un posicionamiento que busca distinguirse del proyecto histórico colonial la modernidad y de la normalización de los cuerpos, presentando el advenimiento de procedimientos gestados en otras dinámicas y en la promoción de otras lógicas, permitiendo(nos) componer universos simbólicos diferentes a los basados en oposiciones binariamente asimiladas. Entonces devienen posibilidades de configurar investigaciones que partan de la comprensión de la descolonización y la desnormalización como categorías heurísticas y como prácticas posibles - e ineludibles - para el conocimiento de sí (RAMALLO, 2018; BERENGENO, 2020), a la vez que se gesta una pedagogía como narrativa y práctica reflexiva del sentido de ser, que confiere centralidad al registro ontológico que complementa a 
la hermenéutica, en la medida en que existen unas relaciones oblicuas aunque innegables entre narración, identidad y subjetividad ${ }^{\text {iv }}$.

En síntesis este texto anuncia la posibilidad de desplazar la completa atención del rigor de la técnica a favor de la presencia erótica; se vuelve entonces una instancia performática que atenta contra la visión instrumental que descorporaliza las mentes en pos de la productividad y la sistematización. El ejercicio narrativo que aquí proponemos considera, en cambio, a la erótica como una forma de conocimiento, como aquella potencia desesquilibrante a través de la cual podemos ir más allá de lo conocido y conocerlo. La erótica nos habla de cómo el ojo inspecciona el fondo y halla la forma de transcribirlo, postpornográficamente (PRECIADO, 2011); entiende que la mirada circula libremente en toda su subjetividad, dialéctica y sensualidad.

En el trazado de las formas eróticas del conocer podríamos decir que en la pedagogía bell hooks (2019), en los tempranos noventa, advirtió la necesidad de reunir la mente y el cuerpo, para sentir y conocer el deseo. Aunque la dimensión sexual no debe ser negada, nos decía, debemos dejar de pensar estas fuerzas sólo en estos términos y abrazar la fuerza motriz que nos impulsa a la autorealización. Por lo tanto, el giro erótico puede explicar cómo conocemos aquello que conocemos. La erótica como límite, como ignorancia y como práctica de lectura también ha sido abordada por Deborah Britzman (2016), quien nos anima a proyectar una mirada no recta o hetero de la pedagogía (entendida aquí como el Gran Relato que pugna por instituir el ser, y el deber ser, de lo educativo en nuestra sociedad). Según esta pedagoga canadiense, la curiosidad, la sexualidad y la producción de placer permiten indagar cómo la educación se ha usado para sustentar desigualdades, normalizaciones y jerarquías sociales. Especialmente en la pedagogía, el discurso teórico queer ha hecho del cuerpo una metáfora que lo aleja de su dimensión material y ha comprendido al erotismo, por su tendencia "femenina" y por su asociación con lo "artístico", como una desviación para reorientar el objetivo de la sexualidad (la procreación) hacia los terrenos de la imaginación y el puro goce sensual (FLORES, 2017).

Además, y tal como esperamos fundamentar aquí, la experiencia erótica tiene un fin en sí misma, su propio sentido y su propia justificación - las cuales no deben comprenderse, no obstante, como marcas de una insularidad. De hecho, lejos de presentarse como una moción estética desprendida de la política y aislada de las urgencias sociales que nos interpelan, la búsqueda de la erótica se anida en lo que Suely Rolnik (2019) define como micropolítica activa con brújula ética. Se trata de un gesto que complementa las sublevaciones macropolíticas, al interesarse por desarmar el cafisheo colonial-capitalístico y recuperar la fuerza de lo vivo por reproducirse (ROLNIK, 2019, p. 117). El plano de inmanencia que también habitamos, en Revista Interinstitucional Artes de Educar. Rio de Janeiro, V. 7, N. 1 - pág. 488-510 janeiroabril de 2021: "Pedagogias Vitais: Corpo, Desejo e Educação" DOI: 10.12957/riae.2021.54178 
paralelo a la cartografía social que inteligimos y verbalizamos, representa una usina de conocimientos con gran capacidad de afectación, así como un reservorio de energía vital y fuerza creativa - el eros al que nos referíamos. La vocación erótica de la investigación es, entonces, también una tecnología de la insurgencia.

Con este sentir y específicamente en el enclave institucional que compartimos, esta búsqueda de la erotización del conocimiento nos ha impulsado a componer una agenda sobre el placer en la docencia universitaria, en las experiencias sensoriales que se despiertan al “observar" una clase y en el proceso de construcción y negociación de los metarrelatos a partir de los informes o registros de observación. Con la firme voluntad de mixturarnos y ensayar promiscuidades fecundas, establecimos oportunamente recorridos de observaciones participantes cruzadas - es decir, concurriendo a las clases de colegas de otra disciplina, en otra Facultad $^{\mathrm{v}}$. Esta decisión ha hecho posible unas dislocaciones (de los cuerpos, los entendimientos) respecto de los lugares comunes y nos impulsó en esa intención original de abrazar una práctica de investigación creativa, sensible a la inmediatez de los vínculos afectivos en los que se goza la docencia universitaria.

Como es posible advertir a esta altura, el artículo ejerce unas licencias respecto de los mandatos y expectativas de la ciencia social convencional - aquella que se apega a los regímenes de control y regulación de las dominancias discursivas. Más que patrullar las fronteras (SOLANA, 2017) entre mente y cuerpo, saber y placer, conocimiento y sentimiento, nuestra disposición a la promiscuidad nos implica en el interés por los tránsitos, en cuyo devenir se manifiestan aglomerados, yuxtaposiciones e hibridizaciones que se parecen mucho a los modos en que se despliega lo vital (dentro y fuera de las aulas universitarias).

Con este espíritu y en pleno ejercicio de ciertas desobediencias, comenzaremos por compartir una breve (carto)grafía erótica de nuestra investigación sobre la docencia universitaria en el territorio local y sus intenciones. Luego, exploraremos las (im)posibilidades de la narrativa como una forma erótica de conocer, para finalmente considerar, desde el plano epistemológico, un movimiento en el que la investigación en sí misma deviene en una práctica erótica afectiva y afectante.

\section{Breve (carto)grafía erótica de una investigación sobre la docencia universitaria}

Creemos prudente comenzar por visibilizar los relieves territoriales más trascendentales - aquellos sobre los cuales se despliegan el resto de las formas y figuras que buscaremos Revista Interinstitucional Artes de Educar. Rio de Janeiro, V. 7, N. 1 - pág. 488-510 janeiroabril de 2021: "Pedagogias Vitais: Corpo, Desejo e Educação" DOI: 10.12957/riae.2021.54178 
cartografiar. Como equipo de investigación reunido en el Centro de Investigación sobre Cultura, Educación Superior y Disciplinas Proyectuales, nuestro interés original se orientaba a la construcción de un corpus de conocimientos y prácticas de articulación entre la investigación narrativa, por un lado, y las didácticas disciplinares - especialmente la proyectual - por otro. En el seno de esta relación, progresivamente se fueron gestando también inquietudes respecto de las fronteras tangibles e inmateriales erigidas dentro del campo de la educación universitaria y sus tradiciones académicas. A partir del Proyecto vigente, nos hemos propuesto transitar, atravesar y mixturar algunas estas fronteras, desmarcando a la investigación de las clausuras categoriales, la infecundidad de los lenguajes referenciales y los absolutos para explorar, en cambio, el territorio impermanente y fluido de una "poética de los saberes"(RANCIERE, 2012) y los aconteceres de la educación. En un movimiento solidario, la trama de la educación universitaria se aborda transcendiendo sus demarcaciones disciplinarias e históricas y abordamos distintos escenarios en los cuales se manifiestan y congregan diversas comunidades de práctica de nuestra Universidad. La enseñanza del derecho, la gestión cultural, las disciplinas proyectuales, la pedagogía y las ciencias de la educación se prestan como narrativas o textos primarios a comprender, con la voluntad de migrar hacia la antimetodología, la indagación post cualitativa y el giro erótico (NORDSTROM, 2017). Estas vertientes epistemológicometodológicas en los márgenes de la investigación social resultan especialmente propicias en función de los rasgos de fluidez e inmanencia que el interés investigativo adquiere.

Es precisamente en el marco de estas geografías que se dibujan posibilidades para ensayar una erótica de la investigación. El relato que sigue, entonces, cobra su pleno sentido en estas coordenadas:

Llegué a la clase de Cristina con cierta timidez y de repente el tiempo que parecía volar comenzó a detenerse. El ojo se agudizó en lo novedoso; estaba en una clase universitaria pero ella no estaba centrada en la exposición de un maestro explicador y los bancos altos del taller que conformaban cada una de las mesas de trabajo me abrumaron por la posibilidad de disponer mi cuerpo de otra manera en una clase universitaria movediza e interrumpida. Saludé a las cuatro ayudantes que la acompañaban y Cristina me presentó como un colega observador. El diálogoinformal- con el equipo de cátedra, también generaba eco en los grupos que iban formándose. Los diferentes grupos de las comisiones en la que los ayudantes de la cátedra se dividen a la cursada delimitaban los espacios de ese enorme salón. Cristina comenzó la clase con una exposición de quince minutos que orientaba a la realización de un parcial inusual: un esquicio.

En nuestro Proyecto de Investigación "La indagación narrativa en la trama de la educación universitaria: poéticas de los saberes y arquitecturas de sentido" compartimos relatos cruzados de observaciones de nuestras propias clases en diferentes contextos 


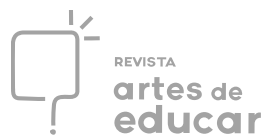

disciplinares: Arquitectura, Gestión Cultural, Derecho, Ciencias de la Educación. La intención primordial es prestar atención a la construcción, también extra y trans-verbal, de los vínculos afectivos que componen las "comunidades emocionales de práctica" (MARTÍNEZ \& YEDAIDE, 2018) y la mixtura de lenguajes con los que podemos capturarlos. Los tránsitos afectivos y afectantes entre los miembros de este equipo suscitan lecturas espejadas y conversaciones espontáneas asociadas a preguntar(nos) ¿cómo nos vemos a nosotros mismos? Esta inquietud se despierta en tanto somos docentes observando y observándonos en nuestras prácticas.

Como en el fragmento que da inicio a este apartado, al investigar como observadores participantes componemos relatos sobre las clases que compartimos. Especialmente lo hacemos a partir de diarios etnográficos, que se transforman luego en el contenido de lecturas también cruzadas y terminan constituyendo una serie de meta-relatos de las observaciones. Lejos de atenernos a un análisis descriptivo, y alertas respecto de la condición de hermeneuta de cada investigador, esta tarea de observar/participar, registrar/interpretar y leer/componer va dibujando para nosotros unas formas brutas que insinúan categorías o líneas de profundización. En el primer meta-relato, específicamente, tres cuestiones asomaron como dignas de atención, a saber, la hospitalidad de la enseñanza y los vínculos afectivos de las comunidades de práctica, los acuerdos y pactos asociados a lo espacial y temporal (¿Cómo describió cada uno el espacio y el tiempo del otro?) y las implicaciones subjetivas para lxs observadorxs, es decir, la reflexión no tanto del "dato recogido" en la observación, sino más bien el sentimiento/conocimiento del proceso de construcción de ese "dato". En la línea de esta tercera vertiente, el interés se condensa alrededor de lo que nos ocurre a nosotrxs al observar(nos).

Nos sucede, por ejemplo, que se retrotrae la prosa:

En una clase que fui a observar, ese taller era una experiencia para salirse de sí misma.

El juego mostraba algunas pistas para el ejercicio, ¿proyectar?

Proyectar se trata de soñar. O mejor aún:

¿Cómo nos vamos a sentar?

Podemos contener al animal que tenemos dentro, Lo salvaje en estado inusual. Hay que circular con esta conversación, Pero ¿Qué es investigar?

Usamos pocas reglas, para no ponerle el cuerpo a un video juego.

¿Qué iremos a representar?

¿Empezamos por nombrar? 


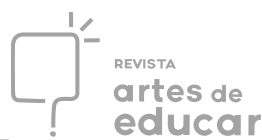

En otras oportunidades, cuando la narrativa y la prosa se sostienen como imprescindibles, se presta no obstante al despojo de sus rituales cientificistas, habilitando el tránsito de la sensualidad:

En esta clase naufragué en el amor...

Para algunxs de nosotrxs, y al intentar abordar los procesos que la propia observación desencadenaba, el registro narrativo (entendido en sentido convencional como ceñido a la palabra escrita) se volvió cada vez más limitado para responder a la magnitud de nuestras preguntas, tan atraídas por aquellas temáticas que eluden la referencia directa. En efecto, las herramientas de reflexión (auto)biográfica de los saberes gestuales, corporales y emocionales asociados a la docencia universitaria que buscamos movilizar ampliaron también sus lenguajes y abrazaron formas en las que la intimidad se con-funde con la sensibilidad. Fotografías, poesías, dibujos y metáforas visuales pasaron a detentar una jerarquía que les es inusual o esquiva en la academia, al ingresar a la investigación como modos válidos aunque refractarios de expresar lo "observado/vivido":

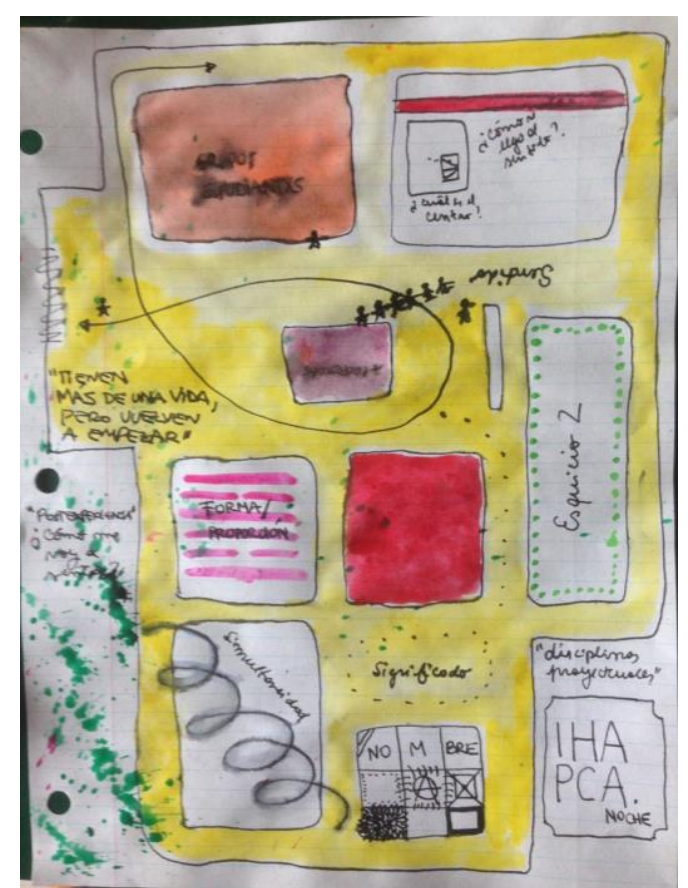

Figura 1: Mapa de la clase de Cristina

En el mapa de la clase de Cristina (Imagen 1) sobre la forma y la proporción en la asignatura Historia I de las carreras de Arquitectura y Diseño Industrial, resaltamos la multiplicidad de aspectos que aparecen en el relato de un aprender y conocer en movimiento. Para nosotrxs, investigadores de las ciencias humanas y sociales, la disposición y el espacio del 
taller propio de las disciplinas proyectuales significó una puesta en escena desnaturalizada y habitada por la aparente asincronía de la labor práctica. Las mesas de trabajo y el abandono de la clase expositiva a favor de la reflexión de estudiantes y docentes con-fundidos, conforman otro mapa de la afectividad para la enseñanza. Si sentipensamos como Rosi Braidotti que " $L a$ afectividad es la medida que rige el valor de verdad contenido en una idea" (BRAIDOTTI, 2015, p. 93), un relieve afectivo como condición basal del territorio de la clase universitaria reviste su propio rigor y validez. Cuando las ideas son proyectiles lanzados en el tiempo, no pueden ser "exactas" ni "falsas", pero pueden ser contundentes cuando se establecen cimientos afectivos en el proceso de pensar. En sintonía, pensar no es, en gran medida, una actividad consciente, en tanto que expresa el deseo de saber, y este deseo es aquello sobre lo que se sostiene. La condición sensible de la proeza cognitiva es, así, su "recámara carnosa y encarnada" (BRAIDOTTI, 2015, P 97).

Comprender la enseñanza universitaria y, aun más, todo aprendizaje que ella propicie como una aventura condicionada por el afecto podría construir la ilusión de separación entre cuestiones que se nos presentan diariamente en profunda imbricación. Pensamiento y sentimiento no serían, en realidad, términos excluyentes de un fenómeno (de aprendizaje en este caso) sino operaciones epistémicas imposibles de evadir aun frente a la integración e indivisibilidad de lo ontológico. Más que una cualidad de la realidad, las separaciones y escisiones parecen ser un efecto del modo (humano) de mirar (AMHED \& SHMITZ, 2014). Tanto la clase en movimiento como el devenir de las intra-observaciones que la observación suscitaba expresaban y reclamaban sincerar la unicidad inquebrantable de la captura.

Esta obstinación en registrar en palabras y dibujos lo que se manifestaba dentro y fuera del taller, en la simultaneidad de estos y otros lenguajes entramados, expandió cierto tipo de "productividad", necesaria especialmente para quienes consideramos que la investigación, en el marco de una universidad pública, debe contribuir a destituir y reinstituir conocimiento social y políticamente relevante. Este reconocimiento exige algunas aclaraciones.

Los efectos de las lógicas de normalización de la práctica investigativa clásica, obsesionados con clasificaciones y con tipos de productividad disciplinada, lejos de ser inocentes o de responder a criterios que se invocan como técnicos y neutrales, constituyen formas de clausura epistémica o cancelación de la erótica en tanto fuerza creadora. Las teorías - como se comprenden aun en el campo académico en términos de leyes, métodos y regularidades - se presentan en esa matriz como construcciones enajenadas, desprendidas de su tiempo-territorio-cuerpo y abstraídas al punto de desentenderse de la posibilidad de una "afectación sensible" (PORTA \& YEDAIDE, 2017).

Revista Interinstitucional Artes de Educar. Rio de Janeiro, V. 7, N. 1 - pág. 488-510 janeiro-

abril de 2021: "Pedagogias Vitais: Corpo, Desejo e Educação" DOI: 10.12957/riae.2021.54178 
Nuestros registros, en cambio, combinan eróticamente diferentes dimensiones. Se trata de contribuciones para el estudio de la docencia universitaria, porque aportan a la compresión de su vida social y demuestran una perspectiva científica fundada, aunque a partir de referentes más osados y disruptivos, pero que compone, no obstante, un relato veraz. Además del mérito estético - que no es decorativo sino cable conductor de una ética (HAN, 2017) - la productividad a la que nos referimos amplía los estándares y se apoya en el uso de analíticas creativas. Abre e invita a respuestas interpretativas, mientras alimenta la reflexividad entendida en términos gruesos como movimientos performáticos. Hay productividad porque hay creación, fuerza vital que irrumpe y se desmarca, una y otra vez, de las prácticas normadas; se rebela, en este mismo acto, contra la productividad comprendida como acumulación de conocimientos o confirmación de hipótesis tendientes a la perfección en el control y la manipulación de los “objetos" sociales.

Esta actitud erótica hacia la investigación impugna, además, el Gran Mito de la Neutralidad - aquel que la Ciencia Moderna no puede sostener ya con argumentos pero que sobrevive plegado en sus regímenes de control vigentes (DENZIN, 2011). Tal como propone Galeano a través de uno de los diálogos que recupera en El libro de los Abrazos, la objetividad es un artilugio para escapar al dolor humano, para no asumir la responsabilidad que como sujetos vivientes nos es ineludible.

En rebeldía, también, frente a esa ciencia que desea pensarse aséptica, entramos a las clases y los talleres reconociéndonos perturbadores de la escena:

\begin{abstract}
En todo los casos me fue posible sentir la perturbación de mi presencia en lo observado, que de ninguna manera resistía una oteada pura o incontaminada. Yo misma, de hecho, me hice consciente de las diferencias que portaba: mi modo de caminar, los accesorios y ropas que vestía, mi forma de llevar el cabello, el maquillaje, la manera de sostener los papeles. Claramente era una intrusa: lo veía en los gestos y las caras de los demás, quienes aun queriendo disimular el interés no podían no reaccionar a la intromisión de este cuerpo extraño que era yo entre ellxs.
\end{abstract}

Pese al énfasis del higienismo, propio de la racionalidad tecnocrática, que se exalta en este tiempo particular del mundo - en el que la ficción de cualquier separación estalla contra la anárquica propagación de un virus - las propias ciencias “duras" reconocen la interdependencia inexorable de lo vivo. La condición de observador externo, no participante, transforma al presunto extranjero en un ignorante, un ingenuo o un negador de la condición entramada, coevolutiva incluso, de la experiencia vital (HARAWAY, 2013). Nosotros asumimos, en cambio, la mezcla y la nombramos para asumir eventualmente la responsabilidad que se anuda a un interés investigativo. 


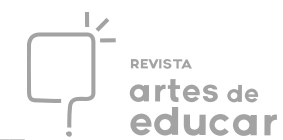

No solamente admitimos, en nuestros registros e intercambios, la perturbación más o menos estridente que implicó nuestra presencia como observadorxs. También reconocemos los lazos afectivos que nos articularon alrededor de Cristina, la Directora del Grupo y del Proyecto. Nos preguntamos, incluso, cómo desconocer que esa mística tejida entre los habitantes del taller parecía un eco de nuestras propias alianzas amorosas y que, entonces, éramos informantes clave de este tráfico de sentimientos.

Allí, también, radica el giro erótico, en ese tránsito del interés por las rigurosidades metodológicas a las maneras en las cuales nos afectamos y erotizamos a partir de lo que conocemos o deseamos conocer. Como contrapeso hemos usado la autenticidad como criterio de validez (KINCHELOE \& MC LAREN, 2012), así como la objetivación que se implica en cualquier acto dialógico, al aludir a significantes comunes que restablecen para nosotrxs la base indispensable del acuerdo y la inteligibilidad.

En estas más inestables condiciones para hacer ciencia, nos hemos también apoyado en la convicción compartida de que este es un camino con corazón, cuya autoridad se asienta en los cuerpos y las formas específicas del conocimiento carnal. También hemos recuperado el énfasis en la marca relacional de la experiencia vital (tan ubicua en los desarrollos científicos de las ciencias más respetadas en nuestros tiempos) para autorizar a los afectos como la capacidad del cuerpo para entrar en relación y ser afectado. Entendemos que la selección de las fuerzas del devenir se regula mediante una ética del goce, afirmación erótica que funciona a través de la transformación de las pasiones negativas en positivas. Esto implica la repetición del placer y la evasión de la tristeza y de las relaciones que la expresan.

Compartimos, finalmente, una imagen que opera de transición entre apartados. Habiendo ya presentado una cartografía erótica de la investigación en nuestros contextos de práctica docente $-\mathrm{y}$ habiendo reconocido la marca afectiva que se registraba como una réplica o un eco entre el afuera (la clase observada) y el adentro (la afiliación a la comunidad de práctica de investigación) - proponemos ahora un movimiento hacia la narrativa y su doble condición, como posibilitadora y a la vez obturadora de la expresión erótica. 


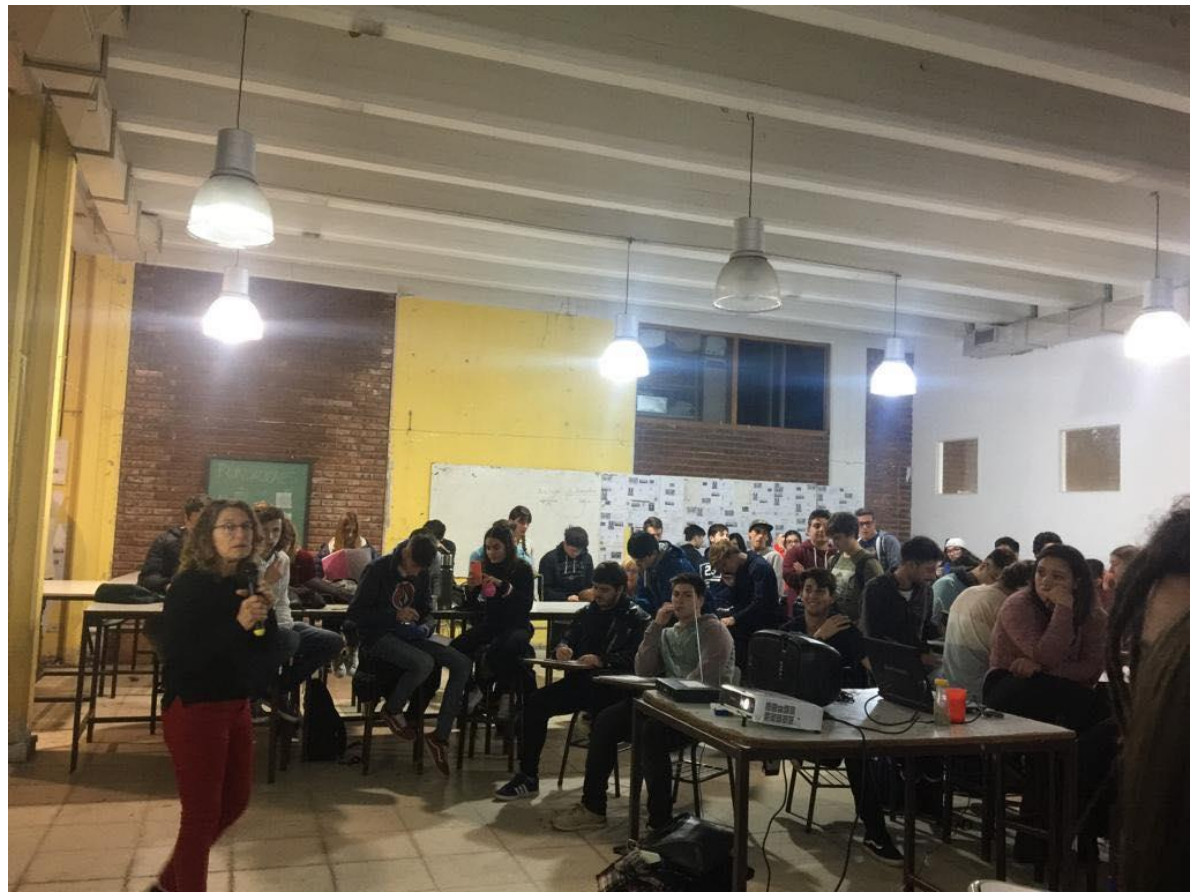

Figura 2: Fotografía de la clase de Cristina

\title{
La narrativa como potencia y límite en la búsqueda de una forma erótica de conocer
}

\begin{abstract}
Salí de la clase y me dejé empapar por la lluvia que caía en esa noche. La confusión y el entusiasmo que me generaba colocarme como observador me generaban algunas dudas difíciles de procesar. Pero como el agua que limpia y que nos muestra un nuevo paisaje, comencé a pensar en la clase de Cristina. Los contrastes, las poéticas de saberes, las mixturas aparecían como gestos que yuxtaponían las luces y las sombras de una misma historia. Cristina se movía y aparecía la sombra de María.
\end{abstract}

La crítica de arte y activista Susan Sontag (1984), en su preocupación por la reducción y empobrecimiento de nuestros mundos, ha colaborado en develar para nosotros los límites de una interpretación que da por supuesta la experiencia sensorial. Leyendo sus textos podríamos decir hoy que, frente a la hipocrática negativa que nos deja solos, las metodologías narrativas y artísticas nos ofrecen una recuperación de los sentidos ocultos y despreciados por el rigor. Nos decía Sontag (1984, p. 30) “debemos aprender a ver más, a oír más, a sentir más”. En lugar (además) de una hermenéutica, necesitamos una erótica.

Si bien diversos paradigmas conviven en el amplio dominio de la investigación cualitativa (DENZIN \& LINCOLN, 2011), en todos ellos el rigor se presenta, expresamente o a modo de insinuación, como una condición constitutiva de toda empresa investigativa. Es cierto que la inscripción en el campo de la academia exige un mínimo grado de sistematización y obediencia normativa, pero entendemos que el exceso de rigor puede encubrir la contraparte Revista Interinstitucional Artes de Educar. Rio de Janeiro, V. 7, N. 1 - pág. 488-510 janeiroabril de 2021: "Pedagogias Vitais: Corpo, Desejo e Educação" DOI: 10.12957/riae.2021.54178 
creativa del proceso, es decir, su erótica. Con esto no estamos prescribiendo que los investigadores debamos erotizarnos; más bien estamos reconociendo que algo de esta fuerza vital queda siempre enredado en la actividad de la investigación, aunque muchas veces disimulada tras el culto pornográfico al rigor y la obediencia de ciertas lógicas históricas (trasvestidas de trascendentales). La erótica como potencia deseante, cognoscente y productora, motiva nuestro quehacer científico permitiéndonos habitar lo que somos en concordancia con lo que hacemos. Entretener la posibilidad de una dimensión erótica en nuestro trabajo nos invita al reconocimiento de las resonancias que en el propio cuerpo provoca el encuentro con otrxs, ya sean saberes, colegas, estudiantes u "objetos" de interés.

Nombrar la erótica es, entonces, una manera de hacer lugar a lo personal imbricado en esos vínculos. Pero, además, "el erotismo es (...) un desequilibrio en el cual el ser se cuestiona a sí mismo, conscientemente" (BATAILLE, 2009, p. 22), y entonces el reconocimiento también genera espacio para comprender nuestro compromiso con lo que investigamos y su origen en la provocación de la inquietud corporal/mental de alguna "ignorancia".

Entonces, hablar de investigación en educación erótica también recupera la idea de que nuestras indagaciones tienen como propósito conocer algo que no sabemos, poner en cuestión algo que creemos saber y dejarnos sorprender con aquello que hallamos y aprendemos. A su vez también alimenta el supuesto de que todo conocimiento es en definitiva autoconocimiento (SANTOS, 2003).

En estos sentidos, entendemos que las aperturas propuestas por los giros queer y afectivo han provocado el costado más radical de los otros giros - lingüístico, hermenéutico e incluso descolonial. Podríamos decir que, de la mano de la sub-versión descolonial, que estimula la desmarcación de las heterarquías binarias (CASTRO GÓMEZ, 2010), los giros lingüístico y hermenéutico fueron torsionados radicalmente hasta caer, incluso, fuera de sí. Lo que hace unos años configuraba un desafío a las posibilidades de acceso a la Realidad y la Verdad, así, en mayúsculas - producto del reconocimiento de la irremediable mediación de la experiencia humana y sus posibilidades (y limitaciones) discursivas - fue desplazándose hacia el destronamiento de lo Humano y la Razón, desnudadas como poco más que meras ficciones históricas.

Desde este estado de situación, la narrativa ha experimentado su versión más inflacionada (YEDAIDE, 2020) y, luego, sus límites. Nos ocuparemos de estos momentos sucesivamente.

La potencia de la investigación narrativa radica, en gran medida, en la consideración de los sentidos posibles que comunican los puntos de vista del investigador (narrador). Habilita, Revista Interinstitucional Artes de Educar. Rio de Janeiro, V. 7, N. 1 - pág. 488-510 janeiroabril de 2021: "Pedagogias Vitais: Corpo, Desejo e Educação" DOI: 10.12957/riae.2021.54178 
entonces, este desbancamiento de la Neutralidad y Objetividad por su condición de infecundidad (no sólo por su naturaleza mitológica, sino más bien por su sequía erótica). Pero, además, los registros de la autoetnografía, que se suscitaron ni bien la narrativa se puso a andar seriamente en la investigación (ya no intuitivamente sino sobre unas premisas bien construidas) han puesto en valor no sólo pensamientos e interpretaciones racionalizadas sino también emociones y vivencias (auto)biográficas que imponen una cierta horizontalización del derecho a decir - una concepción de cientista/narrador singular, emparejado con sus semejantes, en una opción más democrática y comprometido con la justicia social en una "era de incertidumbre" respecto de las formas de conocer (DENZIN \& LINCOLN, 2011). Desde estas lecturas, en la investigación narrativa se reconoce, además, la inestabilidad de lo enunciado, siempre ligada a la fluidez de formas novedosas de pensar más cercanas a quienes se benefician con las acciones científicas. Y si bien aún queda mucho por delante en la revisión de la crítica social que propone la investigación narrativa, no ha sido poco su aporte a la ruptura de los grandes relatos de los paradigmas ontológicos/metodológicos únicos y abarcadores.

Estas interpelaciones a los pilares de las tradiciones científicas más conservadoras otorgan a la narrativa un atractivo singular en el campo de las ciencias sociales, especialmente por sus productividades catalíticas y educativas, esto es, lo que son capaces de co-gestar con otros dominios y actores del cuerpo social. No obstante, las luces de lo queer y el giro afectivo también opacan y comprometen su importancia. La confianza en una esfera más inmanente, adiscursiva o pre-discursiva, de la experiencia humana ha sido discutida ya por muchos años, incluso por figuras enormes como Pierre Bourdieu. Si bien las capacidades humanas para construir mundos con sus historias son cada vez más nítidas, tal y como lo propone Jerome Bruner en su Fábrica de Historias, la construcción de sentido no ha quedado nunca monopolizada por los relatos, ni siquiera en sus versiones orales (las que preservan la impermanencia de lo vivo). Hay sentido que se aloja en los pliegues de las rutinas, los rituales y las prácticas que revisten formas silenciosas pero altamente efectivas. La narrativa, en estos enclaves semióticos, ya no reina ni prevalece.

Esta cualidad incompleta de lo narrativo, en tanto no captura la totalidad de los sentidos performados en un tiempo-espacio, no debiera comprenderse, no obstante, como un impedimento para lo que puede aportar a la erótica y los afectos. Gracias a la narrativa, y su aliento a los acentos hoy colocados sobre la subjetividad, la experiencia y la creatividad humana, se han revalorizado las contrapartes binarias oscurecidas del saber: razón/emoción, mente/ cuerpo-o espíritu-, conocimiento/ignorancia, teoría/práctica, público/privado, normal/anormal, entre otros. 
Sobre el fondo de una racionalidad moderna-colonial cooptada por la prevalencia de la visión (CANDELERO, 2016), las exploraciones de la narrativa han recortado como figura la reflexión sobre nuestras otras capacidades sensoriales. Eve Kosofsky Sedgwick, por ejemplo, nos ha despertado respecto de la intimidad entre el sentir y el tocar al hablar de la "narración activa" - aquella que se enciende en el tiempo en que la textura y la emoción se entraman (SEDGWICK, 2018).

La narrativa, también, como recurso para la interpelación de los grandes relatos y la reinstitución de autoridad discursiva de aquello que ha sido despreciado, e incluso malpreciado (YEDAIDE, 2017), ha colaborado con la resemantización de lo erótico y su recurrencia en ámbitos que le fueran extranjeros - como la investigación en la universidad. El erotismo podría haber sido reducido a su ligazón con la sexualidad y el placer, pero la comprensión del modo en que estas cuestiones establecen interdependencias con la marginalidad social, la patologización y la criminalización (RUBIN, 2018) nos han permitido visibilizar los vínculos antes opacos entre deseo y normalización, afección y arquitectura social. La disidencia sexual empuja el debate, entonces, al plano epistemológico en el que adquiere su sentido la búsqueda de la justicia erótica (RUBIN, 2018).

Audré Lorde también ha colaborado con el ensanchamiento del sentido de lo erótico, al describirlo como un recurso propio enraizado en el poder de nuestro sentir no reconocido o expresado. Los modelos de inferioridad femenina, dirá esta activista feminista, lesbiana y negra, dependen de la anulación de lo erótico como fuente de la información y el poder sobre la vida propio de las mujeres. Así, bajo el influjo del patriarcado afectivo, las mujeres aprendemos a "desconfiar de nuestra reserva de energía, que ha sido calumniada, abusada, devaluada en la civilización occidental" (LORDE, 2016; 13). Se trata de una mediación patriarcal (GUTIERREZ, SOSA \& REYES, 2017) que, en un goteo ubicuo, sutil pero constante, obtura la reproducción de la vida por medio de separaciones articuladas, entre las cuales resaltamos aquí aquella de las mujeres entre sí y con sus creaciones (GUTIERREZ, 2018). El erotismo, en este lente, es la usina que nos reconecta con la fuerza vital de lo natural en un vínculo de interdependencia que el mundo moderno-colonial aniquila.

Es claro como estas tesis, vehiculizadas y hechas audibles en relatos que pugnan por destituir una narrativa maestra de la modernidad-colonialidad, restituyen para el deseo y los afectos validez epistemológica. Desde aquí afirman y estimulan nuestra búsqueda de la erótica en la investigación.

Mediante narrativas, entonces, intentamos construir las bases epistemológicas de la justicia erótica a la vez que atraemos la atención hacia el universo de afectaciones sensibles que Revista Interinstitucional Artes de Educar. Rio de Janeiro, V. 7, N. 1 - pág. 488-510 janeiroabril de 2021: "Pedagogias Vitais: Corpo, Desejo e Educação" DOI: 10.12957/riae.2021.54178 


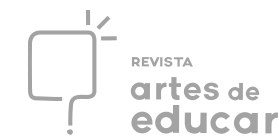

pueblan las prácticas y construyen los sentidos de la docencia universitaria. Entendemos que la creatividad erótica es una fuerza de resistencia (BUTLER, 2015) y que su exposición en la investigación implica el abrazo de un posicionamiento ético-onto-epistémico (KUBY \& CHRIST, 2016) que nos atrae y afilia.

\section{La investigación: del rigor a la erótica}

En medio del tránsito de fuerzas hoy vigente entre la ciencia legitimada y las (otras) diversas formas de conocer, podemos decir que ya se ha superado en gran medida la necesidad de justificar "lo cualitativo" en las ciencias sociales y humanas, lo cual puede y debe ser visto como una conquista semiótica sustantiva a favor de la visibilización del poder político de los usos y fines de la investigación. Esto ha comprometido, por un lado y como adelantáramos, el necesario abandono de las pretensiones universalistas y objetivistas y, por otro, la recuperación del agenciamiento político a manos de lo subalterno y lo abyecto (YEDAIDE, ÁLVAREZ \& PORTA, 2015 p. 28). En las "nuevas" formas de investigar que se han hecho posibles, se procuran medios de validez dialógica, autorreflexiva o contextual (DENZIN Y LINCOLN, 2011), y se desplaza la imagen de la triangulación (como metáfora de una representación confirmada, validada, por la concurrencia de más de una mirada o un instrumento) en pos del prisma, que habilita la consideración de las múltiples superficies que un mismo acontecimiento puede provocar.

En esta nueva concepción ensanchada y plural de lo verdadero, los relatos (tanto aquellos que son sustrato y fundamento de las investigaciones como los que ellas mismas construyen) cobran importancia como potencias retóricas que buscan instituir una o más versiones de lo real. Se presentan, entonces, como un modo de existir, de crear mundos y (re)conocerlos - siempre ceñidos a los condicionamientos de las matrices de percepción que, a modo de grandes relatos pero también rituales o habitus no verbalizados, dominan el espacio semiótico de un tiempo espacio particular.

En la ciencia, como en la vida, el hábito (NORDSTROM, 2018) es tan frecuente y necesario como la variación, y las afectaciones constituyen el combustible indispensable para esta capacidad creadora. Pensar la investigación académica como un sistema abierto, afectable por el tiempo, el espacio, los sujetos y sus interdependencias, implica una recuperación de la mirada relacional que es, también, una óptica promiscua. De ahí que la poética de los saberes (RANCIÉRE, 2012) sea una opción epistemológica tentadora, ya que actúa como una manera Revista Interinstitucional Artes de Educar. Rio de Janeiro, V. 7, N. 1 - pág. 488-510 janeiroabril de 2021: "Pedagogias Vitais: Corpo, Desejo e Educação" DOI: 10.12957/riae.2021.54178 
de romper con la descripción de un narrador omnipresente, que se ubica desde arriba e interpreta a lxs otrxs.

En contraposición, la postura erótica (infectada) busca empatía con el lector, en una posición epistemológica no genética ni central.

Al poner en juego la experiencia, declarar el carácter localizado de los conocimientos que producimos y acreditar el carácter narrativo de las investigaciones, la autenticidad científica se ensancha y garantiza. Se produce a la vez una renegociación necesaria de los términos del "pacto ficcional" (ECO, 1996) aunque desde otros enclaves: ya no desde la historia (argumento) como ficción, sino de la investigación como versión.

Entendemos que esta posición más humilde del investigador nos impide ufanarnos de construir meta-relatos abarcativos o trasplantables; no obstante, la explicitación del punto de vista (que puede ser subjetivo sólo a condición de ser, al mismo tiempo, cultural) es el modo en que asumimos responsabilidad política, desafectando al conocimiento de la ficción que lo concibe entero, total, general o universal.

Este posicionamiento también importa disponernos a dislocar la lógica de nuestro propio desarrollo profesional como privilegiados profesores universitarios, a poblar una pedagogía que se resista a quedarse encerrada entre muros. Más bien iríamos, como sugiere Jack Halberstam (2011), a robar de la universidad y abusar de su hospitalidad, como una forma de estar en ella pero no ser de ella. Se trata de investigar pero rechazar la profesionalización cuando las universidad aplasta, en vez de promover, el pensamiento poco convencional y original.

Efectivamente, la erotización habilita también una fuga de las fuerzas disciplinarias del entorno universitario. Lo disciplinario, tal y como lo definió Foucault (1992) en términos de tecnología de poder moderna, promueve y depende de la normalización, las rutinas, las convenciones, la tradición y la regularidad, y produce expertos y formas administrativas de gobierno. Rechazar las demandas de "rigor", "excelencia" y "productividad" implica comprometerse en la disputa por fomentar y sostener otro tipo de vinculaciones, con mayores proyecciones soberanas para los investigadores.

Si pensamos los saberes y conocimientos académicos como matrices de legibilidad, la fundación (narrativa) de formas de comprender la docencia universitaria que impliquen lo que afecta y es afectado en el proceso (como registro sensorial o emocional, traducible o no a la palabra) constituye una postura erótica (vital, creativa) políticamente liberadora de los regímenes de poder instituidos en el ámbito de la academia. Pero, además, hace justicia al modo de andar de las comunidades emocionales de práctica (en las cátedras, en los grupos de Revista Interinstitucional Artes de Educar. Rio de Janeiro, V. 7, N. 1 - pág. 488-510 janeiroabril de 2021: "Pedagogias Vitais: Corpo, Desejo e Educação" DOI: 10.12957/riae.2021.54178 
investigación) que se entraman precisamente por filiaciones que incluyen las coincidencias intelectuales pero de ninguna manera quedan limitadas a ellas. Mucho de lo que sucede en un aula universitaria se "palpa en el aire", más que plasmarse en documentos curriculares. Detenerse a recuperar estos "puntos ciegos" de las tradiciones pedagógicas y disciplinares que se cruzan en las aulas es una osada decisión a contrapelo de las rutinas y expectativas institucionales; implica un reencantamiento que requiere ser defendido, una y otra vez, de su falta de "seriedad" o "rigor". Claramente se presenta hoy como una contranarrativa, mirada periférica, lenguaje menor o ciencia débil. Sin embargo es la opción epistemológica que mejor dialoga con el cuidado de lo que vive y la responsabilidad frente a la otredad significativa (HARAWAY, 2015).

Indagar, deslizar, explorar, adentrar, sostener, resonar, conectar, compartir, suscitar, aproximar, mirar, relacionar, estar, llegar, mover, conocer, componer, trascender, expandir, restituir, profundizar, vivenciar son algunas de las acciones que propone la investigación narrativa en la educación. Estas acciones que mueven el foco del interés del objeto a la experiencia habilitan un campo semántico que tiene como punto de partida un encuentro, una relación con algo que se siente, que se prueba y a su vez abisma ${ }^{\mathrm{vi}}$. La experiencia siempre es con alguien (o algo) y en esa primigenia relación advertimos el advenimiento de la erótica como marco posible. Al comprender que "hacer una experiencia quiere decir dejarnos abordar en lo propio por lo que nos interpela, entrando y sometiéndonos a ello" (LARROSA, 2002: 58), el investigador es dislocado como sujeto epistémico y reubicado como sujeto empírico. Desde un enfoque más holístico del quehacer científico, que apuesta por la generación de conocimientos situados y compartidos, consideramos que la configuración del investigador como "sujeto pensante no puede separarse de la de un sujeto deseante: la afectividad y la intelectualidad se desarrollan juntas de un modo que hace difícil separar la razón de la imaginación" (BRAIDOTTI, 2015, P 94). Por tanto, como sujetos penso-deseantes-conscientes o no-la erótica nos atraviesa.

También, al abordar los hechos de una investigación a la luz de la experiencia personal y alejarnos de la objetividad de la ciencia, nos acercamos a nuestra corporalidad somática ${ }^{\text {vii }}$. Este deslizamiento, en tanto docentes/investigadores/narradores nos reconfigura como observadores creativos de nuestras realidades en las que vamos recorriendo el espacio que somos, las voces que nos habitan, las historias que nos contamos y los recuerdos que guardamos para explorar aquello que nos interpela y buscarlo. Escribir sobre ello, en lugar de a pesar de ello, se re-configura como una experiencia en sí misma que en un movimiento doble nos reconecta con lo que vivimos y con quienes nos leen. Los aportes del filósofo español Paul Revista Interinstitucional Artes de Educar. Rio de Janeiro, V. 7, N. 1 - pág. 488-510 janeiroabril de 2021: "Pedagogias Vitais: Corpo, Desejo e Educação" DOI: 10.12957/riae.2021.54178 
Preciado nos ayudan a pensar en esas coordenadas cuando afirma: "la escritura es el lugar en el que habita mi adicción secreta y, al mismo tiempo, el escenario en el que mi adicción sella un pacto con la multitud" (PRECIADO, 2011, P.50).

Podríamos, entonces, decir que la escritura como reflejo de un proceso vital interno, como pulsión de encuentro y como pacto con otrxs nos invita a desplazarnos del cientificismo objetivante hacia un cientificismo erotizante que nos une personalmente con aquello que estudiamos. En este contexto el erotismo emerge como posibilidad de tejer un nuevo cuerpo de palabras que nombren esos otros modos de conocer presentes en las narrativas de la educación.

Es claro ya, esperamos, que entendemos que la erótica recorre nuestros cuerpos, deseos y sentires en un doble movimiento: por una parte como esa energía que al pasar por nosotros nos configura nuevamente y, por otra, como aquello que afilia lo corporal, lo afectivo y lo social. Los afectos comprendidos como la capacidad del cuerpo para entrar en relación, tanto para afectar como para ser afectados, nos dan la posibilidad de asumir humilde y responsablemente el lugar que ocupamos, habitar las voces que enunciamos y renunciar a la potestad de decir de otrxs. Arriesgamos que reconocer la erótica que nos atraviesa como un constante devenir propicia otras maneras de conocer, ser, sentir y saber que interpelan la universalidad de la lógica moderno-colonial y sus cimientos binarios. Estas otras formas que promueven la propiocepción, entendida como reconocimiento de nuestra posición corporal en el espacio, colaboran en la desnaturalización de los espacios (físicos, imaginarios y conceptuales) al traer a la superficie la autoconciencia del movimiento propio en la configuración de esos espacios. Como gesto tramático (en el sentido de que genera tramas) el erotismo habilita experiencias en el presente y nos invita a vivir en un mundo más grande. Partiendo de la premisa que conocer es conocerse, develar las dimensiones sexual, afectiva, corporal, contextual, temporal y biográfica (siempre inacabadas y siempre en proceso) que subyacen en nuestras producciones científicas es para nosotros una manera posible de advertir la erótica diseminada en nuestras maneras del investigar. El reconocer estas dimensiones busca encontrar otros criterios de validez que apartados del rigor se aproximen a la erótica en su carácter contextual, dialógico y autorreflexivo.

Entonces, erotizar nuestras prácticas académicas como actos humildes, que reconocen la inestabilidad del control de la autoridad enunciativa en el discurso, permite relativa claridad de la estabilidad de la presencia de la propia voz en el discurso. Esta presencia en la enunciación da cuenta de las maneras en que construimos el mundo como objeto a la vez nos construimos a nosotros mismos (BENVENISTE, 1966 y 1974). La certeza de que los textos que producimos generan narrativas que construyen sus propias versiones de la realidad y convocan a los lectores Revista Interinstitucional Artes de Educar. Rio de Janeiro, V. 7, N. 1 - pág. 488-510 janeiroabril de 2021: "Pedagogias Vitais: Corpo, Desejo e Educação" DOI: 10.12957/riae.2021.54178 
a incorporar esa mirada del mundo social nos participa (por no decir obliga) a encarnar el comprometido rol social, personal y político que nuestras profesiones implican. Narrar la experiencia (o desde la experiencia) no solo evidencia el espacio personal y sensible presente en los modos de hacer investigación, da cuenta también, de la ficcionalidad del rigor positivista que a partir de la diferenciación entre lo ficcional y lo factual, lo objetivo y lo subjetivo, crea dispositivos ficcionales de la realidad pero no los evidencia. Como fuerza transgresora, libertaria y efímera habilita un punto de desequilibrio en el cual el ser se cuestiona a sí mismo deliberadamente; un descentramiento justo que nos sitúa en relación con otrxs y configura un modo de relación que busca comprender las tramas generadas a partir de los afectos y afectaciones en la transversalidad de los conocimientos. Contrariamente a lo que un sentido banal de la erótica podría sugerir, encontramos en ella el punto del equilibrio entre la conciencia individual y el sentirnos copartícipes de lo que sucede en nuestras comunidades. La emergencia erótica como una práctica amorosa, atenta y cuidadosa surge como una condición sencilla para reconocer los cuerpos presentes en las enunciaciones que pronunciamos y los deseos en los objetos (artefactos) que construimos. Considerando que "lo que está en juego en el erotismo es siempre una disolución de las formas constituidas" (BATAILLE 1957, p.14), desde este enclave, el advenimiento de la erótica en la investigación en educación resulta sumamente pertinente por la condición crítica y emancipadora que ella misma comporta.

Es posible concluir, sobre la base de estas reflexiones sentipensadas y deseadas, que la incorporación de la dimensión erótica como forma honesta de revelar lo arbitrario de las prácticas de investigación posibilita una comprensión sutil de nuestros contextos inmediatos, de las comunidades de las que formamos parte y de las relaciones que en ellas establecemos, tanto con otrxs como con nosotrxs mismos; le confiere al discurso científico un poder liberador y de crítica, estimulándonos a considerar lo que creemos esa dimensión inmanente pero silenciada. Como potencia deseante, cognoscente y productora, la erótica abre dentro del lenguaje establecido un espacio vital capaz de afectar y de ser afectados, un espacio capaz de rearticular aquello que el pensamiento binario separó. Como práctica caótica que cuestiona lo instituido, reglado y/o normado, la erótica encuentra su centro en la autoafirmación de sujetos libres que en pos de su autonomía miran al caos de frente, no para ordenarlo sino para dejarse desordenar. Como fuerza revolucionaria, transformadora y creadora, la erótica promueve la restitución del agenciamiento político a partir del proceso reflexivo que nos ayuda a deconstruir viejas concepciones y a poner la vida en el centro de la reflexión y acción transformadora. Finalmente, como una forma nómade y sutil de imaginar, el erotismo nos habilita a restaurar modos más amables con la vida. 


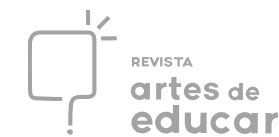

Nos gustaría cerrar advirtiendo que estas reflexiones intiman con el devenir de una investigación narrativa particular, así como con las (des) orientaciones que en ese enclave nos permitimos habitar. Preferimos, entonces, pensar este ejercicio como una escritura en tránsito, un ensayo colectivo erotizado.

\section{REFERENCIAS}

ALVAREZ, Z., PORTA, L y YEDAIDE, M. Pasión por enseñar. Emociones y Afectos de profesores universitarios memorables. Revista Científica Alternativas, Espacio Pedagógico. Universidad Nacional de San Luis. Nº64-65, 2012.

BÁEZ, J y FAINSOD, P. ¿Qué sea ley! Excusas, paradojas y desafíos de la Educación Sexual Integral (ESI). Material del Observatorio Participativo de Políticas Públicas en Educación. Buenos Aires, Facultad de Filosofía y Letras de la Universidad de Buenos Aires, 2018.

BARTHES, R. El placer del texto y lección inaugural. Buenos Aires, Siglo XXI, 2008.

BATAILlE, G. El erotismo. Buenos Aires, Tusquets Editores, 2009.

BENVENISTE, É. Problemas de lingüística general I y II. México: Siglo XXI, 1966 y 1974.

DE SOUSA SANTOS, B. Crítica de la Razón Indolente. Contra el desperdicio de la Experiencia. Bilbao, Desclée, 2003.

HANNA, T. What is Somatics?. En: Somatics, Vol.4-4, p. 4-8. California, 1986.

LARROSA, J. Sobre la experiencia y el saber de la experiencia. En su Más allá de la comprensión: lenguaje, formación y pluralidad. Caracas, Universidad Simón Rodríguez, 2002. Recuperado de: http://files.practicasdesubjetivacion.webnode.es/200000018-9863d9a585/ la experiencia_Larrosa.pdf.

BERENGENO, L. La descolonialidad en el gesto. Un estudio interpretativo de gestiones culturales empíricas a partir de experiencias en la Comunidad de San Marcos Sierra, Córdoba, y Acantilados, Mar del Plata. Tesis de Licenciatura en Gestión Cultural. Mar del Plata, UNMdP, 2020.

BRAIDOTTI, R. Lo posthumano. Barcelona, Gedisa, 2015.

BRITZMAN, D. ¿Hay una pedagogía queer? O, no leas tan recto. Revista de Educación, Mar del Plata, año 7, n. 9, p. 13-34, 2016.

BUTLER, J. Cuerpos que importan. Sobre los límites materiales y discursivos del 'sexo'. Buenos Aires, Paidós, 2015. 
CANDElero, N. Ciencia, Arte, Medios Consideraciones en torno a la experiencia. Primer Congreso nacional e internacional de Educación artística. "Hacia una Educación artística participativa, comprometida, e innovadora"; 3. 4 y 5 noviembre de 2016; Facultad de Humanidades y Artes (UNR). Rosario, Ciudad Gótica, 2016.

DENZIN, N. \& LINCOLN, Y. (comp.) El campo de la investigación cualitativa. Vol. 1. Barcelona, Gedisa, 2011.

DUSSEL, E. Filosofía Ética Latinoamericana: De la erótica a la pedagogía de la liberación. México, Edicol, 1978.

FERRERA BALANQUET, R. (Comp.) Andar erótico decolonial: el desprendimiento. Buenos Aires, Ediciones del signo, 2015.

FLORES, V. Tropismos de la disidencia. Santiago de Chile, Palinodia, 2017.

FLORES, V. Prólogo: Por un feminismo pervertido en Rubin, G (2018) En el crepúsculo del brillo: la teoría como justicia erótica. Córdoba, Bocabulvana ediciones, 2018.

FOUCAULT, M. Microfísica del poder. Madrid: La piqueta, 1992.

GUTIERREZ AGUILAR, R. La lucha de las mujeres contra todas las violencias en México: reunir fragmentos para hallar sentidos. En: Gago. Gutierrez Aguilar, Draper, Menéndez Díaz, Montanelli, Barmet, Rolnik 8M Constelación feminista. Buenos Aires, Tinta Limón, 2018.

GUTIERREZ, R.; SOSA, N. \& REYES, I. El entre mujeres como negación de las formas de interdependencia impuestas por el patriarcado capitalista y colonial. Reflexiones en torno a la violencia y a la mediación patriarcal. Heterotopias, $N^{\circ}$ 1. Facultad de Filosofía y Humanidades, Córdoba, Argentina, 2017.

HARAWAY, D. Manifiesto de las especies de compañía: perros, gentes y otredad significativa. Trad. Isabel Mellén. Córdoba: bucavulvaria ediciones, 2017.

HOOKS, B. Ensinando a transgredir: a educação como prática da liberdade. Sao Pablo, Editora WMF Martins Fontes, 2019.

KUBY, C. \& CHRIST, R. Productive Aporias and Inten(t/s)ionalities of Paradigming: Spacetimematterings in an Introductory Qualitative Research Course. Qualitative Inquiry, Vol. 24 (4), 293-304, 2018.

LARROSA, J. La experiencia de la lectura. Estudios sobre literatura y formación. Buenos Aires, FCE, 2002.

LORDE, A. Lo erótico como poder y otros ensayos. Córdoba, Bocavulvaria Ediciones, 2016.

MARTÍNEZ, C \& YEDAIDE, MM. Pasiones; Juan Manuel Escudero. Mar del Plata, EUDEM, 2018. 
NORDSTROM, S. Antimethodology: Postqualitative Generative Conventions. Qualitative Inquiry Vol. 24 (3) 215-226, 2018.

PORTA, L y YEDAIDE, MM. Pedagogía(s) vital(es): Cartografías del pensamiento y gestos ético-políticos en perspectiva descolonial. Mar del Plata, EUDEM, 2017.

PRECIADO, PB. Manifiesto contrasexual. Barcelona, Anagrama, 2011.

RAMALLO, F. El conocimiento de sí y las pedagogías del ser: Un relato de la experiencia de la escuela El canto del Fuego. Revista Cronía Año 18 - No 14, 48-57, 2018. Recuperado de: http://www.hum.unrc.edu.ar/ojs/index.php/cronia/article/view/718/675.

RANCIÉRE, J. Pensar entre disciplinas. en Frigerio, G y Diker, G (comps.) Educar: (sobre)impresiones estéticas. Paraná, Fundación La Hendija, 2012.

RODRIGAÑEZ, C. Por un feminismo de la recuperación. México, El Reboso Editorial, 2010.

ROLNIK, S. Esferas de la insurrección: Apuntes para descolonizar el inconsciente. Buenos Aires, Tinta Limón, 2019.

RUBIN, G. En el crepúsculo del brillo: la teoría como justicia erótica. Córdoba, Bocabulvana ediciones, 2018.

SEDGWICH, E. K. Tocar la fibra: Afecto, pedagogía, performatividad. Madrid, Alpuerto, 2018.

SOLANA, M. Relatos sobre el surgimiento del giro afectivo y el nuevo materialismo: ¿está agotado el giro lingüístico?. Cuadernos de filosofía $\mathrm{N}^{\circ} 69,87-103$ (julio-dic., 2017).

YEDAIDE, MM, ÁLVAREZ, Z \& PORTA, L. La investigación narrativa como moción epistémico-política. Bogotá. Revista Científica Guillermo de Ockham, 13 (1), 27-35, 2015.

YEDAIDE, MM. Los discursos sobre la enseñanza desde una perspectiva descolonial: Desdibujamientos e inflaciones. En: Porta, L. (org) La expansión biográfica en educación. Colección: Narrativas, Autobiografías y Educación. Buenos Aires, Universidad de Buenos Aires, 2020.

YEDAIDE, M. El relato "oficial” y los “otros" relatos sobre la enseñanza en la Formación del Profesorado. Un estudio interpretativo en la Facultad de Humanidades, UNMDP. Tesis de Doctorado en Humanidades y Artes, con mención en Ciencias de la Educación. Universidad Nacional de Rosario, Argentina, 2017.

WITTIG, M. El pensamiento heterosexual y otros ensayos. Barcelona, Egales, 2006.

${ }^{\text {i }}$ Docente e investigador del Departamento de Ciencias de la Educación de la Facultad de Humanidades
(UNMdP), miembro del Programa Interdisciplinario sobre Estudios Descoloniales (PIED) y del Grupo de
Investigadores en Educación y Estudios Culturales del Centro de Investigaciones Multidisciplinares en
Revista Interinstitucional Artes de Educar. Rio de Janeiro, V. 7, N. 1 - pág. 488-510 janeiro-
abril de 2021: "Pedagogias Vitais: Corpo, Desejo e Educação" DOI: 10.12957/riae.2021.54178 
Educación (CIMED). Maestro en Estudios Étnicos y Africanos (UFBA), Magíster, Profesor y Licenciado en Historia (UNMdP), Especialista en Docencia Universitaria (UNMdP) y en Educación y TICs (ISFD N19). Actualmente es Becario de CONICET y Doctorando en Humanidades y Artes con mención en Ciencias de la Educación (UNR). Su área de trabajo está vinculada a la historia de la educación, las perspectivas descoloniales y la didáctica de la historia. Universidad Nacional de Mar del Plata/ CONICET. Contacto: franarg@ @otmail.com. Dirección institucional Facultad de Humanidades, UNMdP. Funes 3350, Mar del Plata (0223) 4752426. Argentina.

${ }^{\text {ii }}$ Doctoranda en Educación (UNR) y Graduada Adscripta en Departamento de Gestión Cultural. Técnica Superior en Gestión Cultura y Estudiante avanzanda de la Licenciatura en Gestión Cultural. UNMdP. Argentina. iii Docente, investigadora y Directora del Departamento de Ciencias de la Educación y el Centro de Investigaciones Multidisciplinarias en Educación de la Facultad de Humanidades de la Universidad Nacional de Mar del Plata. Docente e investigadora en la Facultad de Arquitectura, Urbanismo y Diseño, UNMDP. Doctora en Humanidades y Artes con mención en Ciencias de la Educación (Universidad Nacional de Rosario), Especialista en Docencia Universitaria y Profesora de Inglés (UNMDP). UNMdP/CONICET. Argentina.

${ }^{\text {iv }}$ Debemos reconocer que respecto de la investigación narrativa podríamos desplegar diversas perspectivas, en un enorme arco que va desde las posturas que asumen el análisis empírico como la reconstrucción de los hechos -a través de un riguroso trabajo documental descriptivo y narrativo -hasta aquellas que se concentran en el estudio de los significados que construyen los sujetos, entendiendo a la narrativa como una inevitable y perpetua transformación de los sentidos de lo vivido. En su mayor tensión posible, el arco admite la pregunta sobre el para qué de los relatos.

${ }^{v}$ Nuestro Grupo de Investigación está compuesto por arquitectos, pero también por actorxs provenientes de la Gestión Cultural, el Derecho y las Ciencias Sociales.

${ }^{v i}$ Recordemos que etimológicamente la palabra experiencia viene del latín experiri, probar. Periri se encuentra también en priculum, peligro y la raíz indo- europea per, marcan la idea de recorrido (perâo, pasar a través; perainô, ir hasta el final; peirô, atravesar, etc.)

${ }^{\text {vii }}$ La somática es un campo que emplea enfoques integrales centrados en el cuerpo o soma. Thomas Hanna acuño el término soma como el cuerpo viviente según es experimentado desde el interior. Desde una perspectiva holística Hanna considera que hablar de la persona como un soma sortea la diferenciación conceptual cerebro-pensamientocuerpo. 